\title{
Internal user satisfaction: challenge for management in primary health care
}

\begin{abstract}
Summary
Among the objectives of primary health care it is to deliver quality care to the population served, for which it is essential to know the degree of satisfaction of internal user.
\end{abstract}

Objective: To identify job satisfaction in municipal health centers of primary care in a district of the city of Santiago, Chile.

Methods: descriptive of cross section in which the instrument Job Satisfaction S20/23 Melia and Peir or was applied with a survey of ca sociodemographic racterización 287 officials at least one year old, in $\mathrm{j}$ ornada minimum of 22 hours.

Results: There is greater satisfaction with the relationship $\mathrm{c}$ on the upper, the monitoring process and satisfaction with their work and higher dissatisfaction with aspects related to the physical conditions at work such as lighting and ventilation and recognition related to promotion opportunities, training and wages.

Conclusion: The results agree in some dimensions as stated in the literature. Most of the factors that generate greater dissatisfaction can be easily corrected by institutions. $\mathrm{T}$ here is finally the need to further investigate the level of job satisfaction in primary care.

Keywords: job satisfaction, primary health care, quality of health care
Volume 3 Issue 2 - 2017

\author{
Dayann Martinez Santana,' Viviana Aliaga \\ Barros, ${ }^{2}$ Sylvia Maria Campos Serrano, ${ }^{3}$ \\ Maria Elisa Fuenzalida Arriagada, ${ }^{4} \mathrm{Paz}$ Soto \\ Sources, ${ }^{5}$ María Paz del Río Cea, ${ }^{6}$ Viviana \\ Muñoz' \\ 'PhD en Enfermería, Profesor Asistente, Escuela de Enfermería, \\ Pontificia Universidad Católica de Chile, Chile \\ ${ }^{2}$ Especialista en Enfermería Familiar y Comunitaria, Profesor, \\ Escuela de Enfermería, Universidad Finis Terrae, Chile \\ ${ }_{3}^{3}$ Magister en Nutrición, Profesor Asociado, Escuela de \\ Enfermería, Pontificia Universidad Católica de Chile, Chile \\ ${ }^{4}$ Enfermera, Departamento de Salud, Ilustre Municipalidad de La \\ Pintana, Chile \\ ${ }^{5}$ Magister en Administración en Salud. Profesor Titular, Escuela \\ de Enfermería, Pontificia Universidad Católica de Chile, Chile \\ ${ }^{6}$ Enfermera, Departamento de Salud, llustre Municipalidad de La \\ Pintana, Chile
}

\section{Correspondence: Dayann Martinez Santana, PhD en} Enfermería, Profesor Asistente, Escuela de Enfermería, Pontificia Universidad Católica de Chile, Chile, Email dcmartin@uc.cl

\section{Introduction}

The basis of the Public Health System in Chile is constituted by the Primary Health Care centers, in which the greatest amount of benefits. ${ }^{1}$ These centers are designed with the purpose of favoring access to those populations with lower resources, reducing the existing gaps. The new model of health care with comprehensive, family and community approach aims to provide a continuum of care, focusing on comprehensive care for families with emphasis on promotional and preventive, promoting self - care and encouraged Healthcare. ${ }^{2}$ Among the objectives of this model is, in an important place, to deliver quality care to the population served. ${ }^{1}$

Cuba-Fuentes et al. ${ }^{3}$ mention that Primary Care teams should, at all times, be in a position to initiate a continuous improvement program and permanently seek evidence to support that the changes have been incorporated into the routine of each center. ${ }^{3}$ Identifying problems or situations for improvement and the choice of opportunities is equally necessary to overcome. ${ }^{4}$ Among the problems identified in health centers that may affect quality management are those related to internal user satisfaction and organizational climate. Being understood as an internal user the human resource that provides the services and benefits to the attached users.

L to internal user satisfaction has been defined as "a positive emotional state resulting pleasurable or a subjective perception of work experience Official". ${ }^{5}$ It corresponds to a general attitude resulting from several specific attitudes that a worker has towards his work and factors related to it, will determine the welfare of workers in workplace. ${ }^{6}$ The importance of improving impact analysis patterns of behaviors that have been presented officials, which adversely affect the performance of the equipment and hence on the quality of services offered in primary care. ${ }^{7}$

Regarding the consequences of a low level of job satisfaction, a dissatisfied staff tends to suffer all kinds of health problems such as headaches, mental health problems, heart disease and stroke, generating a higher rate of major dysfunctional behaviors as absenteeism, labor turnover, personal medical expenses and costs for the company, which will affect the productivity and quality of work. ${ }^{8,9}$

On the other hand, job satisfaction generates a desirable degree of welfare for people with $\mathrm{r}$ increases productivity and quality in the institution. ${ }^{10,11}$ Job satisfaction among workers determines behavior rooting, rooting, permanence, efficiency, differentiation, innovation and adaptation. ${ }^{10}$

There is little research to inquire into job satisfaction among workers in primary health care. The low current interest increases the gap to achieve quality in health centers since the degree of satisfaction of internal users is directly related to the perception of service quality. As Gnecco $\mathrm{G}^{7}$ mentions: "A successful organization, which is concerned with quality management, has among its central objectives the welfare of its workers; The permanent improvement of their working conditions; Granting fair compensation according to responsibilities and performance; Recognize and encourage well-done work; Facilitate the development of workers; Promote and promote their effective participation; identify leaders, among others " ${ }^{7}$ For this reason, and 1 establishment of a quality model it requires necessarily know the job satisfaction of workers, as through job satisfaction is checking the quality of the organization and its internal services. ${ }^{12}$ This study addresses the need to identify the degree of internal 
user satisfaction in primary health care, whose results will develop continuous improvement programs in each of the participating health centers.

\section{Objective}

The objective of this research was to identify job satisfaction of workers in health centers primary care level a commune in the metropolitan area of the city of Santiago, Chile.

\section{Materials and methods}

\section{Type of study}

This work corresponds to a cross - sectional descriptive study, in which the self - employed instrument of Job Satisfaction S20/23 of Meliá and Peiró of the University of Valencia was used to measure the job satisfaction of the internal user. (Meliá and Peiró, 1998, quoted in Chiang, Salazar, and Nuñez, 2007). And a sociodemographic characterization survey.

\section{Population and sample}

The universe consisted of 601 staff members from 7 primary health care centers. The sample was estimated at 250 officials, with $95 \%$ confidence level and variance not greater than 20 points, and $20 \%$ nonadherence. Finally, the sample consisted of 287 officials who agreed to participate freely in this study and signed informed consent. Among the inclusion requirements is that the officials eligible for this study should be working at 2012 fixed or fixed term contract in a minimum of 22 hours and with at least one year within the organization.

\section{Instrument}

The Labor Satisfaction Instrument S20/23 by Meliá and Peiró is validated in Chile by Chiang, et al. 2007 and has a structure of five sections that evaluate satisfaction with: the relationship with their superiors, physical conditions at work, participation in decision making, satisfaction with the work they perform and the recognition they receive. The answers are based on a seven-point Likert scale, from very satisfied to very dissatisfied. This instrument was applied at the national level in the public health sector presenting a high reliability (Cronbach's alpha of 0.925$){ }^{10}$

\section{Statistic analysis}

The satisfaction characteristics were calculated as average scores and their standard deviation, proportions for continuous and categorical variables, respectively. For data analysis SPSS version 19 was used.

\section{Ethical aspects}

This project was approved by the Ethics Committees of the School of Nursing of the Pontificia Universidad Católica de Chile and the Metropolitan Health Service of the South East.

\section{Results}

The implementation of socio-demographic survey characterization showed that most officials said the instrument was female (77\%) sex. As for the category to which the officials belong, the majority is of category B (38.3\%), followed by category C $(27.2 \%)$. The officers who make up each category and their distribution are shown in Table 1.
Table I Distribution of officials according to category

\begin{tabular}{|c|c|c|c|}
\hline Category & Official & $\mathbf{N}$ & $\%$ \\
\hline \multirow{2}{*}{ Category A } & Physiotherapists & \multirow{2}{*}{28} & \multirow{2}{*}{9.8} \\
\hline & Dentists & & \\
\hline \multirow{8}{*}{ Category B } & Nurse & \multirow{8}{*}{110} & \multirow{10}{*}{38.3} \\
\hline & Matron & & \\
\hline & Kinesiologist & & \\
\hline & Social worker & & \\
\hline & Nutritionist & & \\
\hline & Psychologist & & \\
\hline & Kinder garden educator & & \\
\hline & Another professional & & \\
\hline \multirow{5}{*}{ Category C } & Higher level nursing technicians & \multirow{5}{*}{78} & \\
\hline & Nursing assistants & & \\
\hline & Pharmacy auxiliaries & & \multirow[t]{3}{*}{27.2} \\
\hline & Dental Assistants & & \\
\hline & Other (rays, etc.) & & \\
\hline \multirow[b]{2}{*}{ Stay D } & Administrative & \multirow[b]{2}{*}{66} & \multirow[b]{2}{*}{2.3} \\
\hline & Others (cleaning staff, guards, others) & & \\
\hline Do not answer & & 5 & 1.7 \\
\hline Total & & 287 & 100 \\
\hline
\end{tabular}

According to the legal quality of contract, $43 \%$ is the owner or with an indefinite contract, $32 \%$ is contracted (fixed term) and the rest to fees. As for the age of civil servants, a third of them are in the age group between 36 and 45 years. Only 1\% are very young (under 26 years). It should be noted that $2.4 \%$ are over 65 years. In relation to the years of service, the majorities have worked less than 6 years $(28 \%)$ and are followed by a group of civil servants who have been working between 6 and 10 years $(19.9 \%)$.

Job satisfaction survey had a response rate of $53.9 \%$. For the interpretation of the results, the "very unsatisfied" category was approved with note 1 , and the category "very satisfied" with note 7. To facilitate comprehension, notes 5, 6 and 7 were grouped as an acceptable satisfaction to Good. Note 4 was considered as a regular satisfaction with the item and frankly unsatisfied notes below 4 The average score achieved in all of the dimensions that measure job satisfaction was 4.4 (range 4.1 to 5.0). Table 2 shows the frequency distribution of the scores obtained in the 6 health centers. The analysis of each of the dimensions of the scale that measures job satisfaction is described below.

\section{Satisfaction with the relationship with your superiors}

As for satisfaction with the relationship with their superiors, the majority (over $60 \%$ of the officials) evaluates this dimension with a mark above 5, which is an indicator that is satisfied. Less than $20 \%$ evaluate this dimension with a note 4 , which is a sign that the official is regularly satisfied, however, a large group of officials (between 16\% and 20\%) state that they are frankly dissatisfied, as Shown in Figure 1. The worst evaluated aspects are: the way their supervisors judge their task (21\%); The support it receives from its superiors $(20.9 \%)$; And the proximity and frequency with which it is supervised (18.5\%). 
Table 2 Distribution of the responses of CESFAM officials in Labor Satisfaction

\begin{tabular}{|c|c|c|c|c|}
\hline Family health centers(CESFAM) & Total surveyed officials & Average score & Note minimal & Maximum score \\
\hline CESFAM I & 35 & 4.1 & 1.3 & 6.9 \\
\hline CESFAM 2 & 42 & 4.1 & 1.3 & 6.6 \\
\hline CESFAM 3 & 54 & 4.7 & 1.3 & 6.7 \\
\hline CESFAM 4 & 31 & 5 & 2.8 & 6.6 \\
\hline CESFAM 5 & 53 & 4.5 & 1.9 & 6.9 \\
\hline CESFAM 6 & 36 & 4.2 & 1.6 & 7.0 \\
\hline CENTRO 7 & 36 & 4.1 & 2.0 & 6.4 \\
\hline Total & 287 & 4.4 & & \\
\hline
\end{tabular}

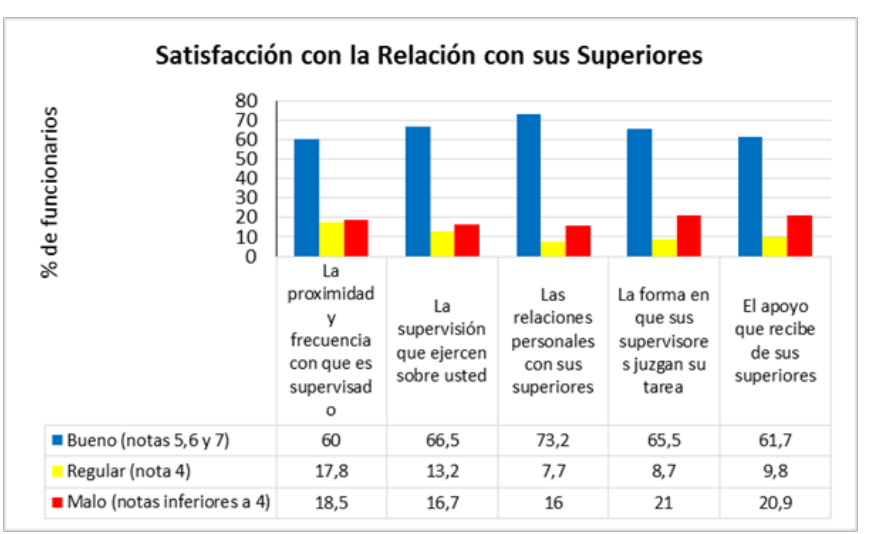

Figure I Labor satisfaction with the relationship with superiors.

\section{Satisfaction with physical conditions at work}

In relation to satisfaction with the physical conditions at work, as shown in Figure 2, the officials express mostly dissatisfaction; On average about $50 \%$ of the officials (48.5\%) evaluated with a score of 1 , 2 or 3 in this regard. The conditions with lower evaluation correspond to the temperature and ventilation and the physical environment and the space that it has in its workplace.

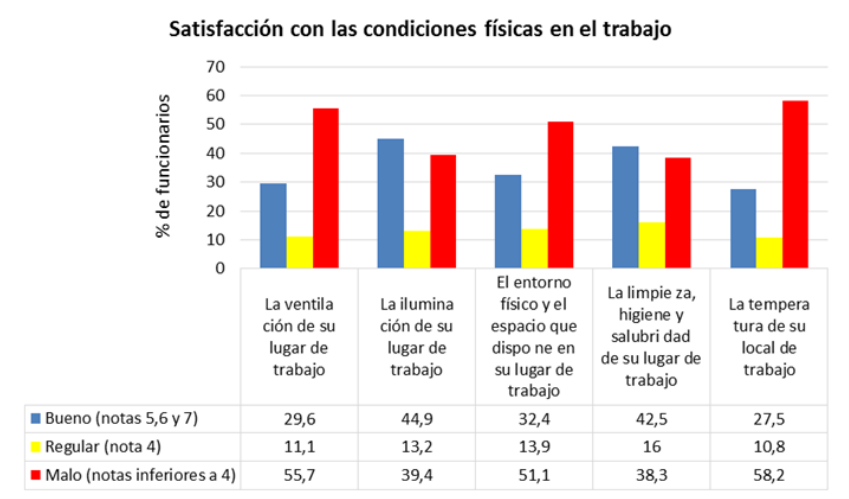

Figure 2 Satisfaction with physical conditions at work.

\section{Satisfaction with participation in decisions}

As shown in Figure 3, of the 6 variables that make up this dimension, 4 are evaluated by about half of the population studied, with a score equal to or greater than 5 , so it is deduced that they are satisfied with their Participation in decisions. In the item "In the equality and fairness of treatment received from his institution" does not reach to be the $50 \%$ that evaluates with a mark superior to 5 , but of equal form is satisfactory. Regarding the way it is given denial in his institution on labor respects a $41.1 \%$ considered adequate form.

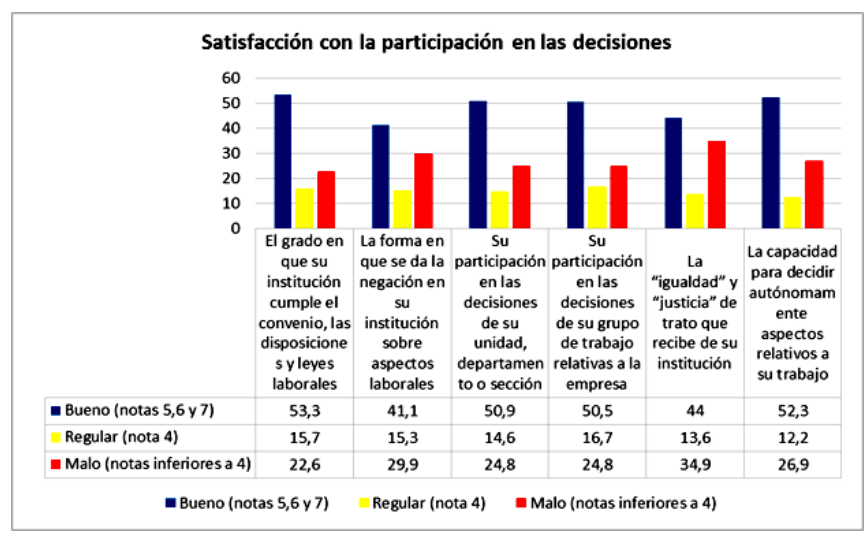

Figure 3 Satisfaction with participation in decisions.

\section{Satisfaction with your work}

As it is shown in Figure 4, and $\mathrm{n}$ this dimension is observed that a high level of satisfaction in all variables over $58 \%$ of the population evaluated note 5 or more. It emphasizes the variable "The satisfaction that produces its work for itself" that reaches the greater percentage $70 \%$.

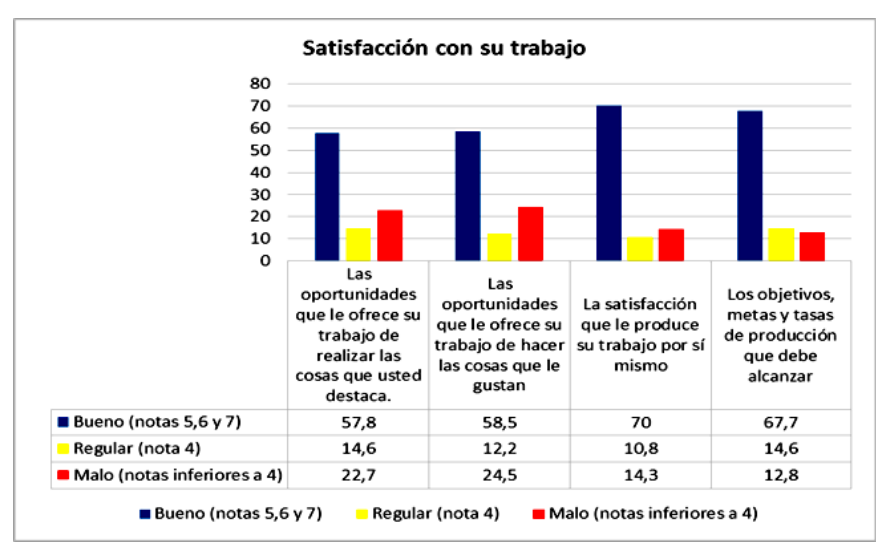

Figure 4 Work satisfaction with work. 


\section{Satisfaction with recognition}

In this dimension it is observed that the degree of dissatisfaction is higher in relation to the other dimensions. As shown in Figure 5, in percentage terms, about $40 \%$ of staff are satisfied and dissatisfied equal proportion, only between 15 and $18 \%$ have a regular satisfaction.

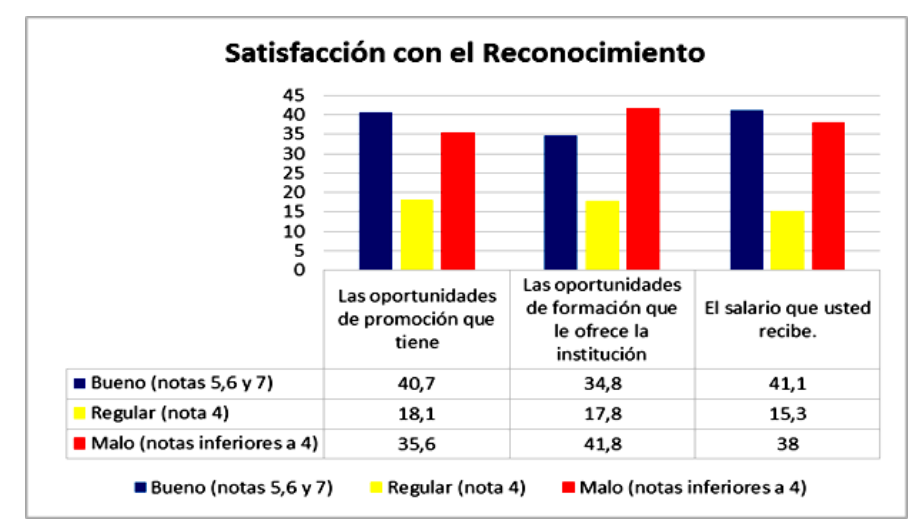

Figure 5 Satisfaction with recognition.

\section{Discussion}

In light of the results, the best evaluated aspects that contribute to job satisfaction among workers in these health centers correspond to the dimensions of job satisfaction and the relationship with his superiors. That is to say, the workers are satisfied with: the opportunities offered by the work of performing the things that you emphasize and like; the satisfaction that his work produces for himself and with the objectives, goals and production rates that must be achieved. In addition, the workers are satisfied with the personal relationships they maintain with their superiors, the supervision process and the support of their managers. In a study by ${ }^{13}$ in Madrid, managerial support received a score slightly below average in contrast to the high level of satisfaction shown in this study, in which about $61 \%$ of staff is satisfied.

With regard to the worst-evaluated dimensions of health center staff in this study, the aspects such as ventilation, lighting, the physical environment and the temperature of workplaces stand out. In a study conducted in hospital nurses in Chile, it was also observed that physical working conditions are a factor of dissatisfaction for hospital nurses, mainly for public sector. ${ }^{8}$ In another study by the Ministry of Social Development Chile, the satisfaction of primary care workers regarding aspects such as ventilation and heating it was also regularly. In this study it is pointed out that only in the middle of the CESFAM heating always worked in winter. Concerning ventilation only $24 \%$ indicated that it had always worked, in contrast to $31 \%$ who stated that it had never worked or that there were no fans or air conditioning. This study indicates that the ventilation function fulfilled doors and windows. ${ }^{1}$

Another aspect was the most dissatisfaction item satisfaction with recognition: Some studies. ${ }^{12}$ mention a low level of satisfaction with promotion and training opportunities offered by the work of primary care workers in their results. In the present investigation the results show a higher level of dissatisfaction in these aspects compared to the rest of the dimensions. Other studies also raise the salaries, promotions and/or promotions factors are those which are most dissatisfied officials, specifically the nurse, and the main subject of these studies. ${ }^{8}$ In a study by.$^{14} 255$ professionals showed that the dimension related to career development dimension was among the ones with lower scores, which in this study was qualified to regulate. According to the twofactor theory of Herzberg there are intrinsic and extrinsic factors that directly affect the satisfaction of workers. ${ }^{15}$

In this study it can be seen that extrinsic factors defined as those that are located in the environment that surround people and cover the conditions in which they perform their work, such as: salary, social benefits, type of management or supervision that The physical and environmental conditions of work, the policies and guidelines of the company, the climate of relations between the company and the people working in it, internal regulations, status and prestige, and Personal safety, among others, are generating both a higher level of dissatisfaction and a higher level of satisfaction in the workers of these health centers. Among the factors that generate a greater degree of dissatisfaction, as mentioned above, they are more significant related ventilation and physical environment. Also, with regard to pay, a higher degree of dissatisfaction demonstrated by the $38 \%$ who are dissatisfied with their salary is observed. Among the extrinsic factors that generate greater job satisfaction is the relationship with superiors obtaining over $60 \%$ in all aspects a good rating. Herzberg states as intrinsic factors causing job satisfaction those related to satisfaction in the position and nature of the tasks that the individual performs such as achievement, recognition and responsibility. ${ }^{15}$ In this study it is observed that satisfaction related to this area is good.

\section{Conclusion}

The current evidence is consistent that high levels of job satisfaction are positively related to the intention to stay in the current position and related to organizational commitment. ${ }^{16,17}$ Primary health care workers in municipal health are more satisfied with their relationship with their superiors, the process of supervision and satisfaction with their work, and the objectives, goals and rates of production that must be achieved and less satisfied with aspects related to the physical conditions at work such as lighting and ventilation and recognition related to promotion opportunities, training and salary concordant with literature.

There is a need to address labor satisfaction in primary health care more deeply, since the greatest number of studies have been done in hospital organizations and there are innumerable differences between these levels of care that prevent extrapolation of results and interventions to the primary level of health. Attention. Job satisfaction enhances efficiency, innovation and adaptation official in the workplace. ${ }^{7}$ The results show that there is potential for improvement in terms of correct satisfaction level los officials with their work, since most of the factors that generate greater dissatisfaction can be easily corrected by institutions. Some recommendations are to improve the ventilation and temperature conditions of the different centers and improve the rotation system of headquarters and training.

\section{Acknowledgements}

None.

\section{Conflict of interest}

The author declares no conflict of interest.

\section{References}

1. Ministry of social development of Chile. Investment projects in CESFAM of primary care, health sector. Chile: Springer; 2009. p. 1-182. 
2. Ministry of health Chile. On the way to Family Health Center. Chile: Santiago; 2008.9 p.

3. Cuba-Fuentes M, Suarez-Bustamante M. Fascículos de educación continua continuous improvement process of quality in primary care. MPA e-journal med. Fam At Int. 2008;2(3):179-184.

4. Four Miller L, Newman J, Murphy G, et al. Problem solving and process improvement as a means of achieving quality; 1997.

5. Locke E. The nature and causes of job satisfaction. In: Dunnette M, Handb editors. New York, USA: Ind Org Psychol; 1976.

6. Bujalance H, Villanueva S, Guerrero S, et al. Burnout and occupational satisfaction of professionals who care for geriatric patients. Rev Esp Geriatr Gerontol. 2001;36(1):32-40.

7. Gnecco G. Internal customer satisfaction; 2010 .

8. Fernández B, Paravic T. Level of job satisfaction in nurses in public and private hospitals in the province of Concepción. Chile Science Sick. 2003;9(2):57-66.

9. Schneider B. Organizational climates: an essay. Pers. Psychol. 1985;28(4):447-479.
10. Chiang M, Salazar C, NuñezA. Organizational climate and job satisfaction in a state health facility: hospital type 1. Theoria. 2007;16(2):61-76.

11. Eleven Rodriguez, Retamal M, Lizana J, et al. Organizational climate and job satisfaction as predictors of performance "evaluation in a Chilean public company". Chile: Talca; 2008.

12. Fernandez M, Moin elo A, Villanueva A, et al. Labor satisfaction of the primary care professionals of area 10 of insalud de madrid. Rev Esp Salud Publica. 2000;74(2):139-147.

13. Fernández M, Villagrasa J, Gamo M, Vásquez J, Cruz E, et al. Study of job satisfaction and its determinants in health workers in an area of Madrid Rev Española Salud. 1995;69(6).

14. Herzberg F. Work and the nature of man. Cleveland. USA. The world of Publishing Company; 1973.

15. J Sawatzky, Enns C. Exploring the key predictors of retention in emergency nurses. J Nurs Manag. 2012;20(5):696-707.

16. Wang L, Tao H, Ellenbecker C, et al. Job satisfaction, occupational commitment and intent to stay among Chinese nurses: a cross-sectional questionnaire survey. $J$ Adv Nurs. 2012;68(3):539-549. 